\title{
Research Article \\ KAIROMONAL FACTORS ENHANCING THE PARASITIZING EFFICIENCY OF THE LARVAL ECTO-PARASITOID, Braconhebator SAY ON PIGEONPEA POD BORER, Helicoverpa armigera (HUBNER)
}

\author{
GUPTA SHIMLA*, RANA NAVNEET, GANGULI JAYALAXMI, GAURAHA RASHMI AND DEOLE SONALI
}

Department of Entomology, College of Agriculture, Indira Gandhi Krishi Vishwavidyalaya, Raipur, 492 012, Chhattisgarh, India

*Corresponding Author: Email-guptashimla27@gmail.com

Received: February 18, 2018; Revised: February 22, 2018; Accepted: February 23, 2018; Published: February 28, 2018

\begin{abstract}
The present experiment was carried out in the Bio-control laboratory, Department of Entomology, Indira Gandhi Krishi Vishwavidyalaya, Raipur, during 201718, in which six kairomonal factors namely; fresh larval extract, larval body wash in distilled water and hexane, larval frass (excreta), matured larvae and maintaining field condition as control, were tested to look for the factors enhancing the parasitizing efficiency of Braconhebetor say. (Hym: Braconidae) against pigeonpea pod borer, Helicoverpa armigea (Hubner). Results revealed that, mature larvae and larval frass (excreta) were highly preferred by $B$. hebator as compared to larval extract, body wash in distilled water, body wash in hexane and over control.
\end{abstract}

Keywords-Pigeonpea, Pod borer, Braconhebator, Parasitization

Citation: Gupta Shimla, et al., (2018) Kairomonal Factors Enhancing the Parasitizing Efficiency of the Larval Ecto-Parasitoid, Braconhebator Say on Pigeonpea Pod Borer, Helicoverpa armigera (Hubner). International Journal of Agriculture Sciences, ISSN: 0975-3710 \& E-ISSN: 0975-9107, Volume 10, Issue 4, pp.-5172-5174.

Copyright: Copyright@2018 Gupta Shimla, et al., This is an open-access article distributed under the terms of the Creative Commons Attribution License, which permits unrestricted use, distribution and reproduction in any medium, provided the original author and source are credited.

Academic Editor / Reviewer: Yogita Shrivas

\section{Introduction}

Pigeonpea (Cajanus cajan L.) is considered as one of the most important legume crop of India, belonging to the genus Cajanus of family Fabaceae. It provides high quality vegetable protein to human beings and is one of the sources of animal feed and fire wood. Carbohydrates (67\%) and protein (22\%) are main constituents of pigeonpea seeds [1]. Pigeonpea is the second most important pulse crop of India after chickpea. India is the largest producer and also the largest consumer of pulses in the world. It accounts for 33 percent of the world area and 25 percent share in global production [2].

The yield levels of this crop are not very encouraging. Among the factors responsible for low yield, the damage caused by insect pests is one of the major factors in pigeonpea. It is attacked by several insect pests from seedling stage till harvesting. Alarming pests array of more than 250 insect pests is surely an area of concern in pigeonpea pest management [3]. Total of 30 insect pests were found feeding on pigeonpea. Among the borer complex of pigeon pea, one pest Helicoverpa armigera (Hubner) was recorded as major pests on this crop by causing approximately more than 51 percent damage to the crop, but Exelastis atomosa (Walsingham), Melanagromyza obtusa (Malloch), Marucavitrata (Fabricius), were recorded as moderate pests by causing damage between 31 to 50 percent [4].

Indiscriminate use of pesticides in pigeonpea under intensive agriculture has led to many problems like health hazards, environmental pollution, adverse effect on beneficial organisms and development of resistance in insect pests towards chemicals resulting in an unsustainable and non- profitable farming system. This led to the introduction of various biological aspects to avoid problems faced by the farmers.

The braconid (Hymenoptera: Braconidae) is a cosmopolitan, gregarious, idiobiont polyphagous, ecto-parasitoid which lays large, yolky eggs on the integument of its host and parasitizes the larvae of Lepidoptera, Coleoptera and Diptera. Braconid is an important biological control agent for several insect pests $[5,6]$. It occurs, naturally, throughout the world. There is growing evidence that $B$. hebetor can also be an important bio-control agent of Helicoverpa armigera [7]. Minimum and maximum developmental days of female was recorded 17.06 and 18.10 days in pea and pigeon pea reared larvae, respectively [8].

Kairomones are inter-specific semio-chemicals which mediate interactions beneficial to organisms that detect them. The use of kairomones for biological control of insect pests has been of interest for several decades [9]. The present investigations were, therefore, undertaken to search for kairomonal factors enhancing the parasitisation efficiency of larval parasitoids on pigeonpea pod borer, Helicoverpa armigera.

\section{Materials and Methods}

The experiments were carried out in the Bio-control laboratory, Department of Entomology, Indira Gandhi Krishi Vishwavidyalaya, Raipur, during 2017-18.

\section{Rearing of the larval parasitoid Braconhebetor:}

Braconhebator was mass multiplied using sandwich technology on laboratory reared Corcyra larvae. Newly emerged adults of $B$. hebetor were paired (male and female) in small plastic container (100 ml). A small drop of honey was put in thewall of the container as food. Few full grown larva of $C$. cephalonica were released on the muslin cloth covering the container and covered again by a piece of muslin cloth (sandwiched) and tied securely with the help of a rubber band, and allowed the parasitoid to oviposit on the host larva for 24 hours. After parasitization parasitized larvae were collected and placed individually into a petridish ( $90 \mathrm{~mm}$ in diameter) for cocoon formation.

For testing the kairomonal factors enhancing the parasitizing efficiency of larval parasitoid, $B$. hebator on pigeonpea pod borer, $H$. armigera, six treatments [Table1] were tested on plastic basin $(28.3 \mathrm{~cm})$ covered muslin cloth under laboratory conditions. 20 pairs of $B$. hebator were collected with the help of an aspirator and released inside the plastic basin and covered with muslin cloth and tied securely 
with the help of a plastic string. On the upper surface of the muslin cloth different treatments (matured larvae of $H$. armigera, were released in all the treatments) were placed and covered with the help of a small petridish to prevent the escape of the larvae. Observations were recorded after $48 \mathrm{hrs}$. and the number of egg laid on the larvae were counted in each treatment. On the basis of the number of eggs laid, preference of $B$. hebator was computed. The experiment was repeated five times

Table-1 Treatment details for enhancing the parasitization efficiency of larval parasitoid Braconhebator on pigeonpea pod borer

\begin{tabular}{|c|c|l|}
\hline S. no. & No. of Treatments & \multicolumn{1}{|c|}{ Treatments } \\
\hline 1. & $T_{1}$ & Larval extract obtained from freshly crushed larvae \\
\hline 2. & $\mathrm{~T}_{2}$ & Larval body wash in distilled water \\
\hline 3. & $\mathrm{~T}_{3}$ & Larval body wash in hexane \\
\hline 4. & $\mathrm{~T}_{4}$ & Larval excreta/frass \\
\hline 5. & $\mathrm{~T}_{5}$ & Mature larvae \\
\hline 6. & $\mathrm{~T}_{6}$ & Control (pigeonpea leaves+ buds+ flowers+ 1-2 larvae) \\
\hline
\end{tabular}

\section{Result and Discussion}

Table-2 Effect of different kairomonal factors on the parasitizing efficiency of the larvalecto parasitoid B.hebetor on larvae of pigeonpea pod borer, $\mathrm{H}$. armigera

\begin{tabular}{ccc}
\hline S. no. & Treatments & Egg laid \\
\hline 1 & T1 & $3.4(1.89)$ \\
2 & T2 & $3.2(1.67)$ \\
3 & T3 & $1.6(1.51)$ \\
4 & T4 & $12.6(3.65)$ \\
5 & $\mathrm{~T} 5$ & $14.6(3.93)$ \\
6 & $\mathrm{~T} 6$ & $0.7(1.26)$ \\
\hline & SEm \pm & 0.63 \\
& CD at 5\% & 0.72 \\
& C. V. (\%) & 33.14 \\
\hline
\end{tabular}

Note: Figures in parenthesis are square root transformed values.

T1: Larval extract obtained from freshly crushed larvae

T2: Larval body wash in distilled water

T3: Larval body wash in hexane

T4: Larval excreta

T5: Mature larvae

T6: Control (pigeonpea leaves+ buds+ flowers+ $1-2$ larvae)

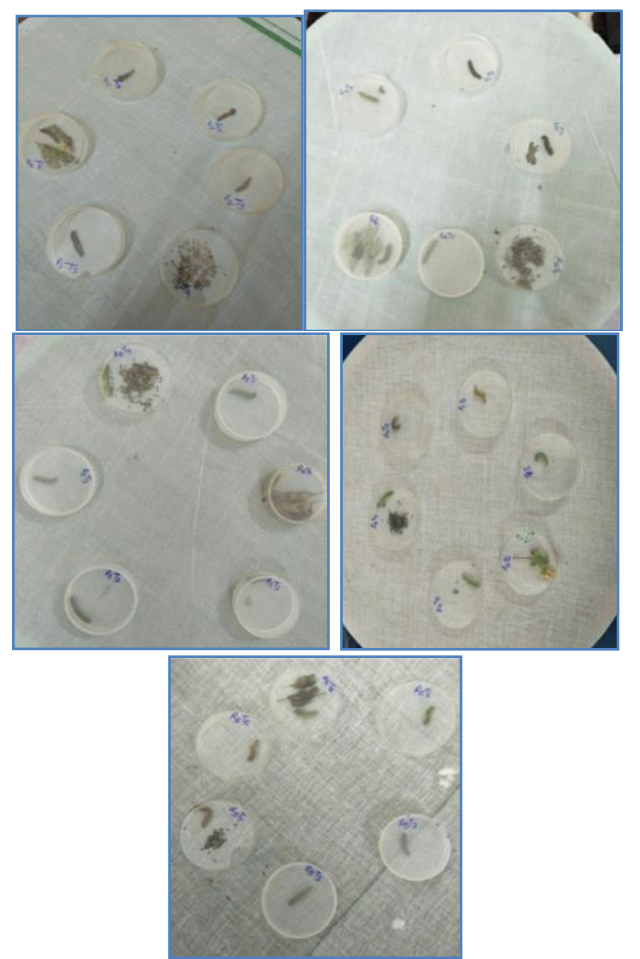

Fig-1 Testing of kairomonal factors enhancing the parasitizing efficiency of the larval ecto-parasitoid, Braconhebator Say on pigeonpea pod borer, Helicoverpa armigera (Hubner)

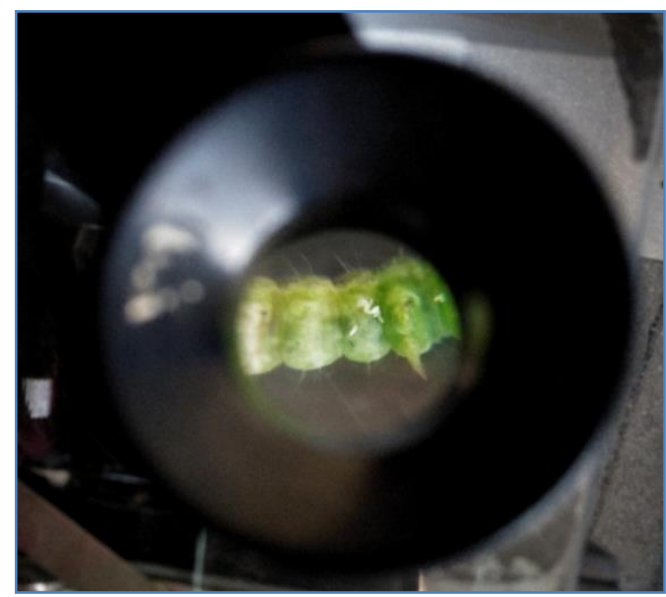

Fig-2 Egg layed by larval ecto-parasitoid, Braconhebator Say on pigeonpea pod borer, Helicoverpa armigera (Hubner)

The application of different factors (treatments) to the host larvae affected the oviposition behavior of female parasitoid for egg laying. Ovipositing females locate their host through kairomonal effect of their host. Results exhibited that highest there were significant difference among the treatments. Highest number of egg laying by $B$ hebator was seen in T5(14.6) followed by T4 (12.6), T1( 3.4), T2(3.2), $\mathrm{T} 3(1.6)$ and least in control T6( 0.7) showing that presence of mature larvae and larval frass (excreta) increased the egg laying by $B$. hebator in comparison to larval extract, body wash in distilled water, hexane and control. Deviation from the present studies were reported by[10]stating that the ectoparasitoid female $B$. hebetor parasitoid of Mediterranean flour moth Ephestiakeuhniella larvae, responded to hexane extract and the parasitization rate increased significantly over control.

Ovipositing females were found to locate their hosts probably via trails containing semiochemicals produced in the mandibular gland of the host larvae. Once the host was located, the female $B$. hebetor injected venom, which resulted in complete paralysis of hostlarvae within 15 minutes, the venom blocks neuromuscular transmission at a presynaptic site and apparently has no effect on heartbeat or midgut function. After the host was paralyzed, the female oviposited, usually placing a clutch of several eggs on the ventral surface of the host or on the side that was in contact with the substrate [11]

Thus, collection and placing mature $H$. armigera larvae and its frass in holed plastic containers in pigeonpea fields at different spots can be done to enhance the parasitizing efficiency of $B$. hebator. The results need further confirmation in field.

\section{Conclusion:}

Pod borer complex is the main point of decline in the production of pigeonpea, for the management of which the farmers directly use insecticides, which is not right for humans and the environment. Therefore, to overcome these problems, the use of living organism as natural enemies leads to sustainable production of this crop. In current research work, the larval-ectoparasitoid (Braconhebetor say.) of pigeonpea pod borer [Helicoverpa armigea (Hubner)] was tested in laboratory for kairomonal factors enhancing the parasitizing efficiency of Braconhebetor on their host insect to maximize production leval of this crop. In which the mature larva and larval excreta/ frass were most effective as kairomonal effect, while the larval extract, body wash in distilled water, body wash in hexane were less effective, compared to the mature larva and larval excreta/ frass.

Application of research: This research is also useful in protecting the production of pigeonpea in lower costs, as well as to protect the environment against the losses done by over use of insecticides.

\section{Research Category: Parasitizing efficiency}




\section{Abbreviations:}

C.D.-Critical difference

C.V.-Coefficient of variation

SEm-Standard error of the mean

ml-Mililiter

mm-Milimiter

cm-Centimeter

Acknowledgement / Funding: Author are thankful to College of Agriculture, Indira Gandhi Krishi Vishwavidyalaya, Raipur, 492 012, Chhattisgarh, India.

*Principle Investigator: Dr. Navneet Rana, Scientist University: Indira Gandhi Krishi Vishwavidyalaya, Raipur, 492 012, Chhattisgarh

Research project name or number: $\mathrm{PhD}$ Thesis

\section{Author Contributions:}

Shimla Gupta- Design of the experiment, data collection, data analysis and interpretation, drafting the article, Critical revision of the article and final approval of the version to be published.

Dr Navneet Rana- Design of the experiment, data analysis, guidance in interpretation and facilities to conduct the experiment.

Dr Jayalaxmi Ganguli- In-charge of the Bio-control laboratory where the experiment was conducted, designed the experiment helped in data analysis, guidance in interpretation and facilities to conduct the experiment, Critical revision of the article and final approval of the version to be published.

Rashmi Gauraha- Data collection

Dr Sonali Deole :Guideline for article

Author statement: All authors read, reviewed, agree and approved the final manuscript

\section{Conflict of Interest: None declared}

Ethical approval: This article does not contain any studies with human participants or animals performed by any of the authors.

\section{References}

[1] Faris D.G. and Singh U. (1990) Pigeonpea Nutrition and Products. In: Nene, Y.L., Hall, S.D.and Sheila, V.K. (eds.) The Pigeonpea. Wallingford, C.A.B. International. pp. 401-434.

[2] Srivastava S. K., Sivaramane N. and Mathur V. C. (2010) Agricultural Economics Research Review, 23,137-148.

[3] Sharma H. C., Clement S. L., Smith T. J., Ranga Rao G. V., Bouhssini M., Ujagir R., Srivastava C. P. and Miles M. (2008) In: Forth International. Conference of Food Legumes Research. Indian Society of Genetics and Plant Breeding, New Delhi, India. pp. 522 - 544.

[4] Balikai R. A. and Yelshetty S. (2008) Legume Research, 31(2), 120-125.

[5] Heimpel G.E., Antolin M.F., Franqui R.A., Strand M.R. (1997) Biological Control, 9, 149-156.

[6] Darwish E., El Shazly M. and El Sherif H. (2003) J. Stored Prod. Res., 39 (3), 265-276

[7] Nikam P.K. and Pawar C.V. (1993) J. Appl. Entomol., 115, 210-213.

[8] Ghirtlahre S. K.(2018) Ph.D. Thesis, Indira Gandhi Krishi Vishwavidyalaya, Raipur, Chhattisgarh.

[9] Baskaran R. K. M., Sharma K. C., Kaushal P, Kumar J., Parthiban P., Senthil-Nathan S. and Mankin R. W. (2017) Physiological and Molecular Plant Pathology, pp. 1-13

[10] Shonouda M. L. and Nasr F. N. (1998) Journal of Applied Entomology, 122, 33-35.

[11] Hagstrum D. W. and Smittle B. J. (1978) Environmental Entomology, 7, 596-600. 